\title{
The Effects of Saddle Alignment and Pedal Stroke Training on a Competitive Cyclist with Anterior Knee Pain: A Case Report
}

\author{
Tim Evens \\ Agility Sport and Spine of Tucson Arizona, tevens@agilitypt.com \\ Jerome Danoff \\ George Washington University - Milken Institute School of Public Health, jdanoff@gwu.edu
}

Follow this and additional works at: https://nsuworks.nova.edu/ijahsp

Part of the Musculoskeletal System Commons, Physical Therapy Commons, and the Sports Sciences Commons

This Case Study has supplementary content. View the full record on NSUWorks here: https://nsuworks.nova.edu/ijahsp/vol17/iss3/3

\section{Recommended Citation}

Evens T, Danoff J. The Effects of Saddle Alignment and Pedal Stroke Training on a Competitive Cyclist with Anterior Knee Pain: A Case Report. The Internet Journal of Allied Health Sciences and Practice. 2019 Jan 01;17(3), Article 3.

This Case Study is brought to you for free and open access by the College of Health Care Sciences at NSUWorks. It has been accepted for inclusion in Internet Journal of Allied Health Sciences and Practice by an authorized editor of NSUWorks. For more information, please contact nsuworks@nova.edu. 


\title{
The Effects of Saddle Alignment and Pedal Stroke Training on a Competitive Cyclist with Anterior Knee Pain: A Case Report
}

\begin{abstract}
Background: Among competitive cyclists, anterior knee pain is a common overuse injury. Alignment of the rider on the bicycle and the loading pattern on the pedals are proposed as factors in this pain. The patient was a 23-year-old competitive female cyclist who was riding up to 200 miles weekly and had developed bilateral anterior knee pain within the 3 months preceding our examination. The purpose of this case report is to demonstrate the effectiveness of adjusting this patient's static alignment (ie. position while seated on bicycle, but not actively pedaling) on the bike and modifying her habitual pedaling pattern. Methods: The patient was analyzed using both static and dynamic measures of alignment while on her bicycle. Her bicycle seat was raised and moved rearward, and her pedaling force output was analyzed using a Computrainer ${ }^{\mathrm{T}}$. Over a 4-week period, she was taught to modify her pedaling force using video biofeedback. Outcomes: After adjustments and training, she could ride for over 3.5 hours without knee pain. Visual analog scale pain score improved from 6/10 to 0/10; Lower Extremity Functional Score improved from 65 to 79; and Knee Injury and Osteoarthritis Outcome Score improved from 81 to 98.5. Clinical Relevance: This case illustrates how application of biomechanical principles and training in pedaling movement patterns can be effective at eliminating knee pain in competitive cyclists. While rest, decreased training volume, and appropriate medication should be considered as treatment components, we believe the initial treatment for competitive cyclists should include biomechanical evaluation of alignment and pedaling pattern.
\end{abstract}

\section{Author Bio(s)}

Tim Evens, PT, DPT is a senior staff therapist at Agility Sport and Spine, Tucson, AZ. He is also a highly competitive bicycle racer and marathoner.

Jerome Danoff, PT, PhD is Professor Emeritus from the George Washington University Department of Exercise and Nutrition Sciences, Milken Institute School of Public Health. He rides bicycles frequently, but slowly. 


\title{
IUAHSP \\ The Internet Journal of Allied Health Sciences and Practice
}

Dedicated to allied health professional practice and education

Vol. 17 No. 3 ISSN 1540-580X

\section{Effects of Saddle Alignment and Pedal Stroke Training on a Competitive Cyclist with Anterior Knee Pain: A Case Report}

\author{
Tim Evans ${ }^{1}$ \\ Jerome Danoff ${ }^{2}$ \\ 1. Agility Sport and Spine \\ 2. George Washington University \\ United States
}

\begin{abstract}
Background: Among competitive cyclists, anterior knee pain is a common overuse injury. Alignment of the rider on the bicycle and the loading pattern on the pedals are proposed as factors in this pain. The patient was a 23-year-old competitive female cyclist who was riding up to 200 miles weekly and had developed bilateral anterior knee pain within the 3 months preceding our examination. The purpose of this case report is to demonstrate the effectiveness of adjusting this patient's static alignment (ie. position while seated on bicycle, but not actively pedaling) on the bike and modifying her habitual pedaling pattern. Methods: The patient was analyzed using both static and dynamic measures of alignment while on her bicycle. Her bicycle seat was raised and moved rearward, and her pedaling force output was analyzed using a Computrainer ${ }^{\mathrm{TM}}$. Over a 4-week period, she was taught to modify her pedaling force using video biofeedback. Outcomes: After adjustments and training, she could ride for over 3.5 hours without knee pain. Visual analog scale pain score improved from 6/10 to 0/10; Lower Extremity Functional Score improved from 65 to 79 ; and Knee Injury and Osteoarthritis Outcome Score improved from 81 to 98.5. Clinical Relevance: This case illustrates how application of biomechanical principles and training in pedaling movement patterns can be effective at eliminating knee pain in competitive cyclists. While rest, decreased training volume, and appropriate medication should be considered as treatment components, we believe the initial treatment for competitive cyclists should include biomechanical evaluation of alignment and pedaling pattern.
\end{abstract}

Key Words: knee pain, bicycle adjustments, biofeedback 


\section{BACKGROUND}

Riding bicycles for exercise, pleasure, and low-cost commuting to work has become increasingly popular in the United States and other countries. ${ }^{1}$ Unfortunately, a common problem among bicyclists is anterior knee (patellofemoral) pain often associated with a combination of overuse (high mileage) and anatomical factors such as bony alignment. ${ }^{2-4}$ In bicycling, the rider's position is fixed upon the bicycle but can be modified to alter the forces distributed through the rider's body, especially in the lower extremities (LEs). Little literature exists confirming exact guidelines on proper rider alignment, but loose guidelines have been established for optimal knee angles and orientation relative to the bottom bracket (center of the two crank arms, see Appendix: Nomenclature). 5,6 Several variables associated with saddle position (height, anterior-posterior alignment, angle, seat design) have been identified as possible factors affecting trunk alignment and biomechanical loads on the rider. $4,6,7$ Bicycle shop mechanics often make adjustments in these variables when preparing a bicycle for a new rider. 8.9

In this case report two key position variables were considered. First, saddle height has been shown to significantly impact the compression force between the patella and the femoral groove. This is because when the saddle is too low, there is a greater knee flexion angle and a greater compressive force component from the quadriceps resulting in greater compression through the patellofemoral joint. 5,10 When this is compounded by a high volume of riding, anterior knee pain may result. Increasing saddle height (up to $100 \%$ of trochanteric height) can decrease the forces upon the patellofemoral joint.11,12 Second, saddle anterior-posterior alignment is typically established when the crank arm is in a forward position parallel to the ground (forward stroke cycle, see Appendix: Nomenclature), and patellar alignment is referenced to the pedal axle (Figure 1). Positioning the rider too forward when the crank arm is in this position will also increase knee flexion (more acute angle) and increase patellofemoral compression. ${ }^{6}$ Therefore, manipulation of both saddle height and anterior-posterior alignment may influence knee flexion angles and concomitant compression forces in the patellofemoral joint.

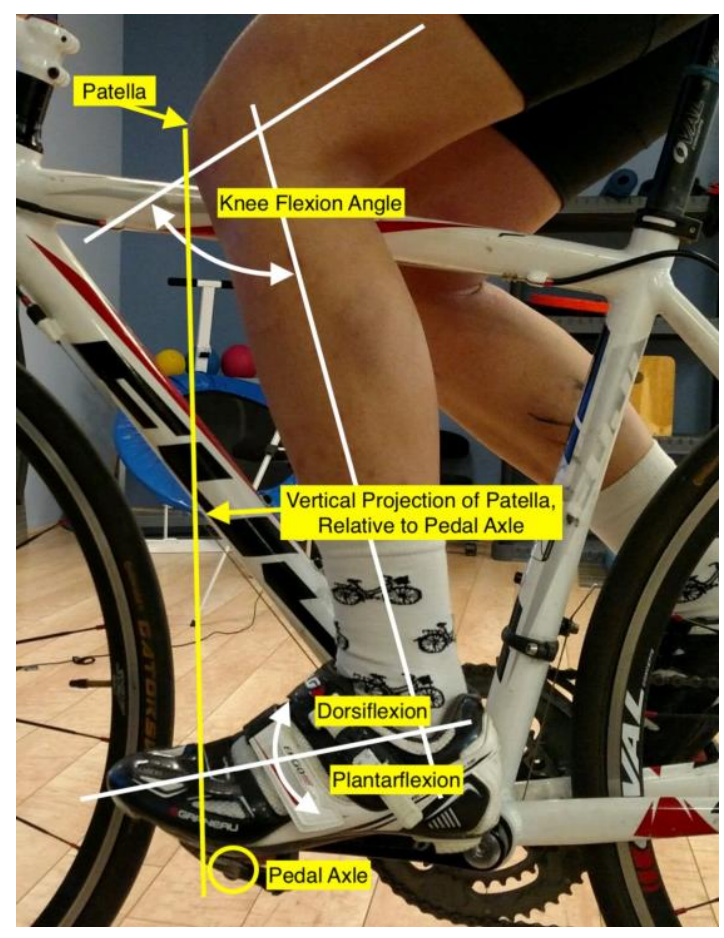

FIGURE 1: Patellar alignment anterior to pedal axle; knee and ankle angles

Because a rider's pedaling form involves linkage of the femur, tibia, and tarsal (ankle) bones, a rider's technique (pedaling form) may affect forces transmitted through the anterior knee. In trials where subjects utilized visual feedback on force output, activity of the vastus lateralis (part of the quadriceps group) was decreased and biceps femoris (part of the hamstrings group) activity increased, thereby reducing patellar compression but still maintaining pedaling torque. ${ }^{2} \mathrm{~A}$ study on ankle position showed that when riders reached the bottom of the stroke cycle (near full knee extension) with higher dorsiflexion angles, there was an increase in 
electromyographic (EMG) activity of the gastrocnemius and decrease in gross mechanical efficiency. ${ }^{13}$ This suggests that having riders maintain their ankles neutral to slightly plantar flexed during peak force production may increase pedaling efficiency. While this ankle position is not natural to most riders, we believe that with biofeedback via sagittal plane video, most riders can become comfortable with this pattern.

Although there are loose guidelines known among bicycle shop mechanics based on anecdotal experiences, minimal research exists supporting optimal positions for alignment, force production, and injury prevention. We believed that adjusting the parameters of this rider's position on her bicycle, in particular the saddle height and anterior-posterior position, would reduce her level of pain while riding. We also believed that video feedback could be used to help this bicyclist successfully adapt to a pedaling position that would be more comfortable during her long and intense rides. Therefore, the purpose of this case report was to describe the application of these principles to a high mileage bicyclist resulting in the elimination of her debilitating knee pain and a return to full participation in bicycling.

\section{CASE DESCRIPTION}

This case study was carried out at a local physical therapy clinic and was approved by the clinical director. The patient signed a consent form and release of information.

The patient was a 23-year-old female in excellent health and physically active. She was an avid cyclist, and had been biking up to 200 miles/week using both road and mountain bikes, but the majority of her riding was done on her road bike. She reported knee pain $(R>L)$ associated with her riding beginning 3 months prior to her arrival in our clinic. She had not received any medical treatment before our examination. Before becoming a cyclist, the patient had been a competitive runner specializing in $5 \mathrm{~K}$ races.

\section{EVALUATION AND EXAMINATION}

The patient's medical history included chronic anterior knee pain associated with running; otherwise, she had no pertinent medical issues. All LE ranges of motion were within normal limits, and there was no palpable pain on either knee.

At the time of initial evaluation, the patient reported that knee pain occurred while riding at a moderate pace and worsened as she increased her riding mileage. Pain began as early as 1 hour into a ride and would linger into the following day after rides greater than 2 hours. She had not received radiograph imaging of her knee and had not been taking medication for her condition.

Her average daily pain was marked on a visual analog scale (VAS), and her level of function was measured using the Lower Extremity Functional Scale (LEFS) and the Knee Injury and Osteoarthritis Outcome Score (KOOS). Her Pre-intervention scores are shown in Table 1.

TABLE 1. Patient evaluation scores, pre and post intervention.

\begin{tabular}{lll}
\hline & Pre-Intervention & Post-Intervention \\
\hline Visual Analog Scale (VAS) & $4 / 10$ & $0 / 10$ \\
\hline Lower Extremity Functional Scale (LEFS) & $65 / 80$ & $79 / 80$ \\
\hline $\begin{array}{l}\text { Knee Injury and Osteoarthritis Outcome Scale } \\
\text { (KOOS) }\end{array}$ & $81.1 / 100$ & $93.5 / 100$ \\
\hline Minimum Knee Flexion, Bottom Stroke Cycle & $45^{\circ}$ & $25^{\circ}$ \\
\hline Maximum Knee Flexion, Top Stroke Cycle & $110^{\circ}$ & $95^{\circ}$ \\
\hline Ankle Angle, Forward Stroke Cycle & $1^{\circ}$ dorsiflexion & $6^{\circ}$ plantarflexion \\
\hline
\end{tabular}

\section{INTERVENTION}

\section{Overview}

At the initial evaluation, saddle positioning on her road bike was raised to reduce the flexion of her knee throughout the stroke cycle (Figure. 2). Her knee flexion angle range decreased as listed in Table 1. We also utilized biofeedback via video analysis to allow her to observe her habitual pedaling form and a Computrainer ${ }^{\mathrm{TM}}$ system to record and display the forces she exerted on the bicycle. She was instructed to develop a rotational force pattern and to reduce her ankle dorsiflexion at bottom stroke cycle. We believe that these changes improved her ability to push down on the pedals without producing knee pain and enabled a more even force distribution throughout the entire stroke cycle. 


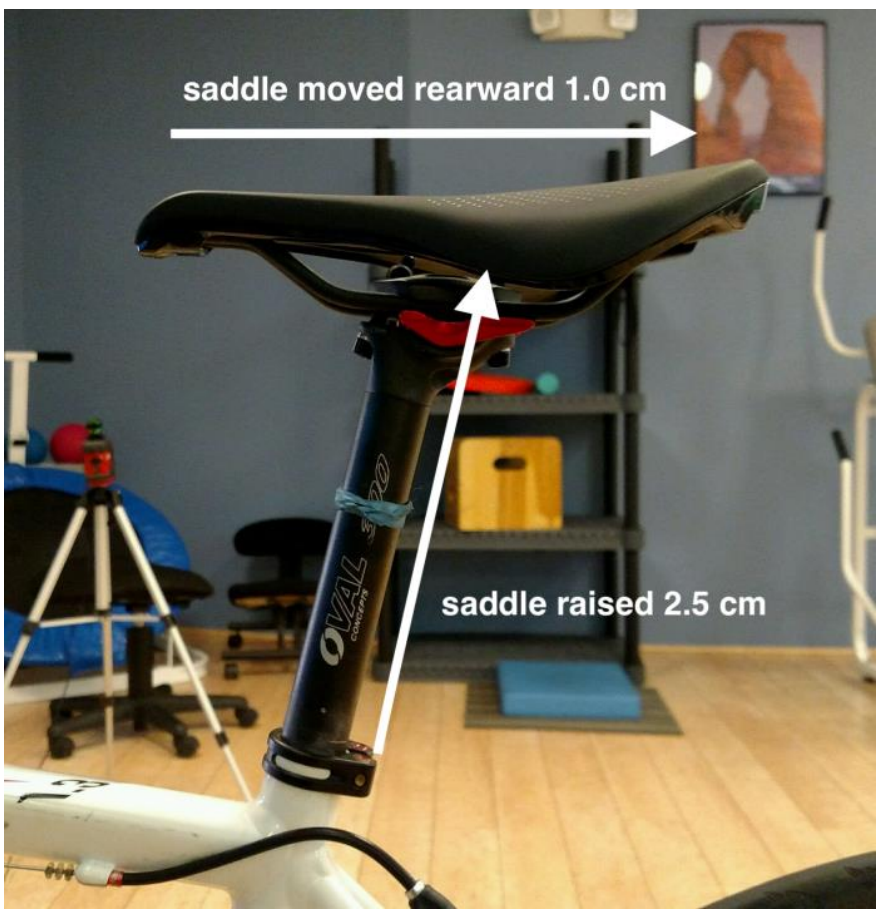

FIGURE 2. Saddle height and horizaontal location adjustments

Follow up visits were once weekly for 4 weeks. After initial changes in position were made, she was instructed to limit her riding intensity and keep rides to 1 hour or less for one week as she adapted to the changes. After one week, she was reassessed using biofeedback video and Computrainer ${ }^{\mathrm{TM}}$ analysis and shown to be consistently pedaling with a neutral to plantarflexed ankle at the bottom stroke and fairly constant force output throughout the stroke cycle. At this time, she was cleared to return to unrestricted riding mileage.

\section{Alignment Adjustments}

The saddle was raised $2.5 \mathrm{~cm}$ and moved rearward $1.0 \mathrm{~cm}$ (Figure 2) to achieve reductions in the patient's knee flexion (Figure 3). The result was a knee flexion angle of 25 degrees at bottom stroke cycle and better alignment of the patella with the crank arm at forward pedal position (Figure 1). After these initial changes in saddle height, she complained of increased pressure through her perineum. We addressed this problem by replacing her initial saddle (width of $145 \mathrm{~mm}$ ) with a wider model (155mm) (Figure 4). This allowed her to be more weight bearing through her ischial tuberosities and less through her perineum. Prior to changing her saddle, she was observed to position herself in a posterior pelvic tilt, probably to alleviate perineal pressure. When using the new, wider saddle, she was able to maintain neutral lumbar alignment. This also put her trunk alignment (angle of greater trochanter to glenohumeral joint to wrist; i.e. shoulder flexion angle when in riding position) at 90 degrees which she found more comfortable for her back (Figure 5). 


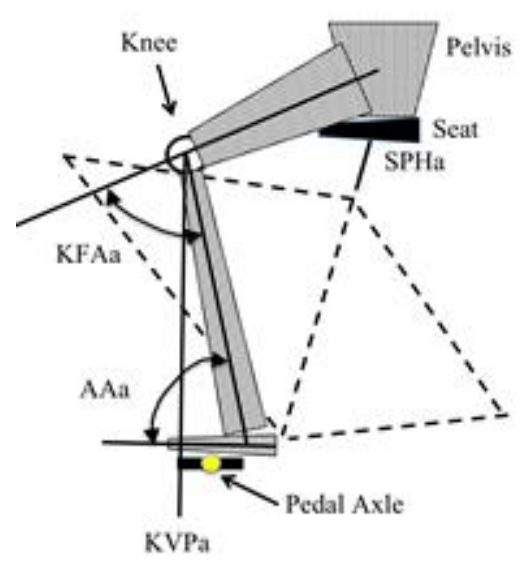

4a. Pre intervention; lower saddle height

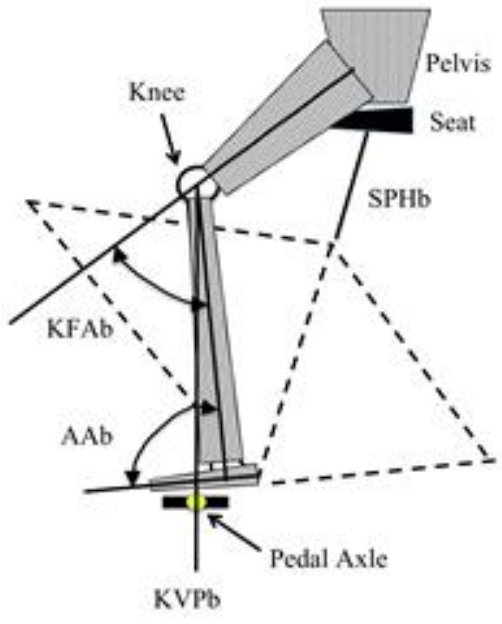

4b. Post intervention; higher saddle height

FIGURE 3. Alteration of lower extremity alignment after saddle height is raised; A, pre-adjustment, B, post-adjustment. Saddle Post Height: SPHb > SPHa; Knee Flexion Angle: KFAb < KFAa; Ankle Angle: AAb > AAa; Knee Vertical Projection: KVPb through pedal axle, KVPa anterior to pedal axle.

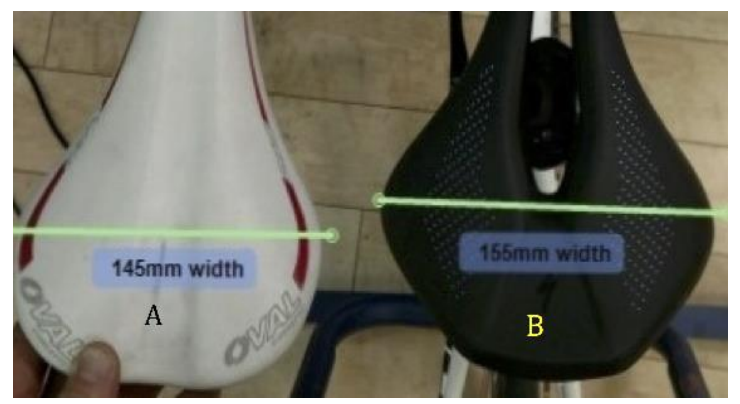

FIGURE 4. Original saddle (A) and new, wider saddle (B).

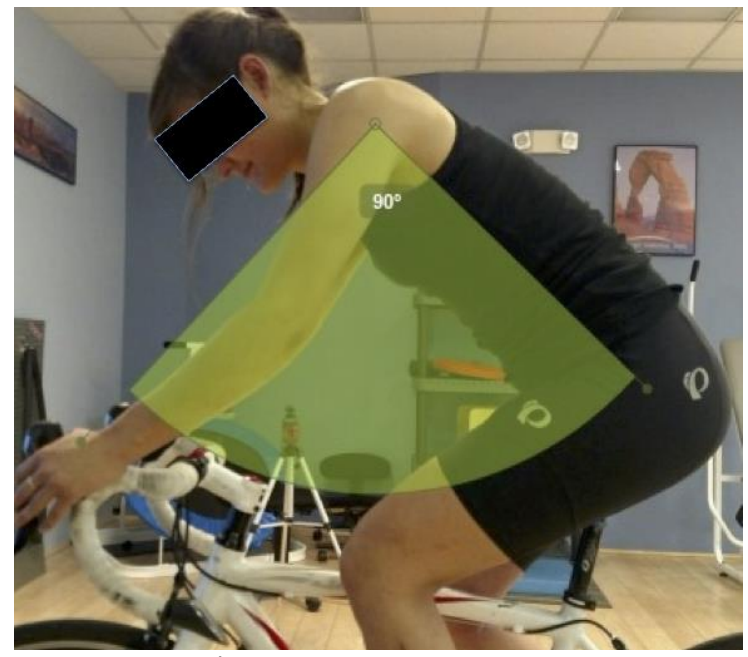

Figure 5. Trunk/shoulder alignment

(C) The Internet Journal of Allied Health Sciences and Practice, 2019 


\section{Computrainer ${ }^{\mathrm{TM}}$}

Computrainer ${ }^{\mathrm{TM}}$ is a biofeedback system similar to a standard cycling trainer but with the ability to monitor and display force output throughout the stroke cycle..$^{13}$ This system provides a graphic display that allows the rider to visualize and compare right versus left forces as well as observe when in the stroke cycle forces are higher or lower (Figure 6). During weekly visits to the clinic, the patient used the Computrainer ${ }^{\mathrm{TM}}$ to confirm that she was applying forces evenly distributed throughout her stroke cycle. We also used simultaneous video of sagittal plane movements to compare hip, knee, and ankle angles to the Computrainer output.

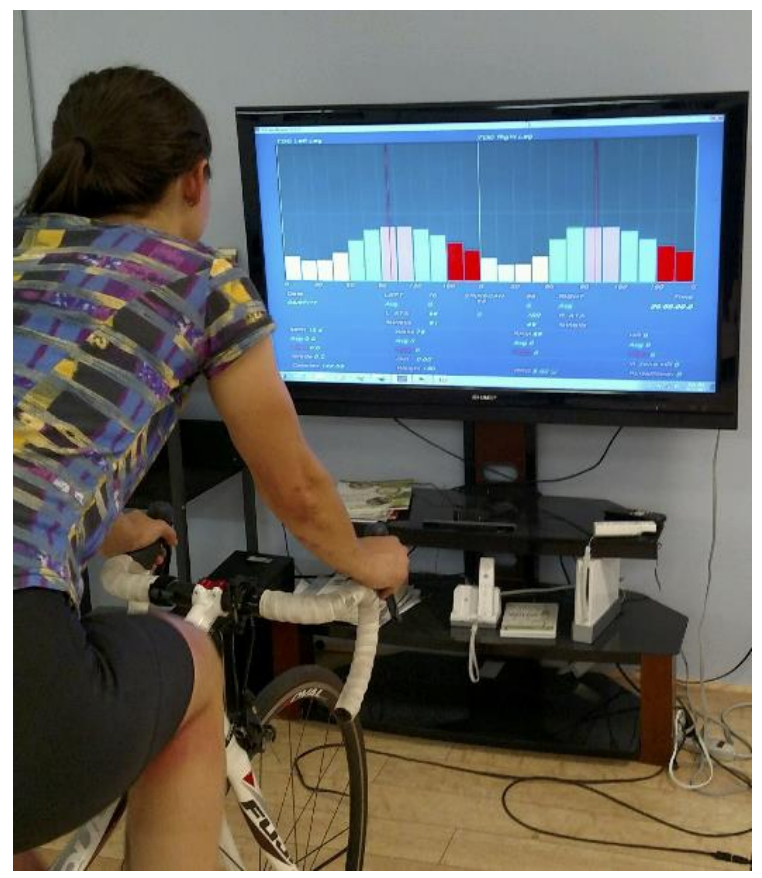

FIGURE 6. Patient viewing biofeedback from Computrainer ${ }^{\mathrm{TM}}$ while riding.

The Computrainer ${ }^{\mathrm{TM}}$ provides analysis of power output, and the patient was asked to maintain a power output of 125 watts which corresponded to a medium effort level for this experienced rider. This level of intensity allowed her to ride for an extended period of time and produced smooth, consistent data. She was found to be producing $4 \%$ greater power with her right lower extremity. For both LEs, her highest power output occurred when the crank arm was at the $40^{\prime}$ clock position (120 past top stroke cycle) and was directed downwards. There was minimal application of force across the top and bottom segments of the stroke cycle. This pattern has been associated with quadriceps activity and high patellofemoral loads. ${ }^{14}$ Also, at the time of peak force production, the patient's ankle was in slight dorsiflexion, a pattern that minimizes contribution of the plantar flexor muscles. ${ }^{15}$ Table 1 includes pre- and postintervention ankle angles recorded at forward stroke cycle $\left(90^{\circ}\right)$, which is just before peak power output $\left(120^{\circ}\right)$.

With feedback from the Computrainer ${ }^{\mathrm{TM}}$ graphic, the subject was able to alter her force output to more evenly distribute forces around the entire stroke cycle. She was given verbal cues to pedal "circles versus straight downwards." She was also reminded to decrease the amount of dorsiflexion at the bottom of her pedal stroke cycle (i.e. produce more plantarflexion effort). As she made these changes in her stroke cycle pattern, her power output also became approximately equal comparing right to left.

\section{OUTCOMES}

The subject adjusted the seat position of her mountain bike to be similar to what we had done with her road bike, and she was able to ride consistently on either bike without limitation in her distance or intensity of output. She reported that her time spent riding prior to pain onset increased "dramatically." She also noted a decrease in pain throughout her cervical spine (which she had not previously reported). After 4 weeks, she was discharged, and communication continued via email for 4 months to ensure that her symptoms had not returned. 
This patient's pre- and post-intervention evaluation scores are summarized in Table 1. No pain was registered via the VAS, and improvement for LEFS and KOOS showed 14 and 12.4 point increases respectively. A minimum clinically significant difference for the LEFS is between 9-12, and a change of 10 or more for the KOOS has been suggested as clinically significant. ${ }^{16,17}$ Therefore, VAS, LEFS, and KOOS scores all showed clinically significant improvement associated with a decrease in disability and pain. These changes also relate to improvement seen generally in activities of daily living (ADLs) as she reported no longer having pain when ascending and descending stairs.

\section{DISCUSSION}

The original force pattern depended heavily on quadriceps muscle activity to extend the knees and push down on the pedals. In this pattern, plantarflexors did not contribute to pedal rotational forces. The newly established pattern allowed greater contribution of the hamstrings, gluteals, and plantarflexors to the force production. Several studies have used EMG data to determine where different muscles contribute to the ideal stroke cycle. ${ }^{18-22} \mathrm{~A}$ simplified schematic summation of these patterns is shown in Figure 7 . She noted that when her graphic readout on the Computrainer ${ }^{\mathrm{TM}}$ was showing nearly equal force output right versus left and when force output was fairly even throughout the stroke cycle, there was a sensation of producing more power through her gluteal, hamstring, and calf musculature (plantarflexors). She also reported a decreased sensation of quadriceps "burning" when working at high loads.

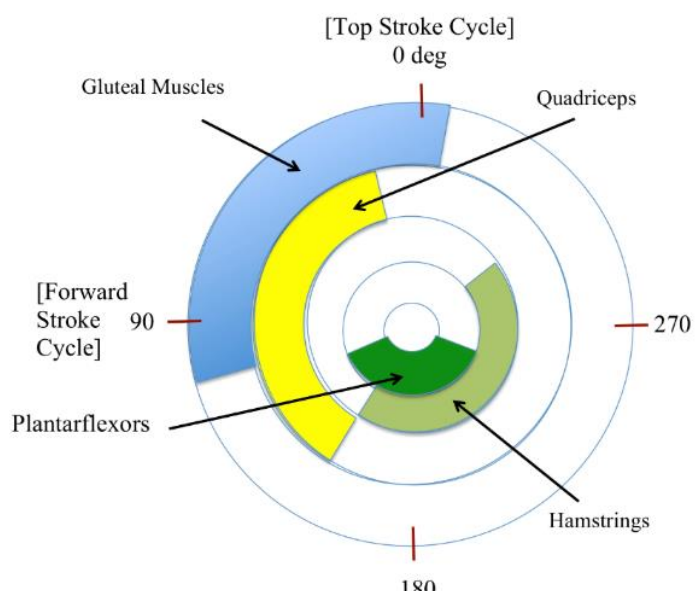

[Bottom Stroke Cycle]

Figure 7. Simplified contribution of muscle groups during pedal stroke cycle. Adapted from references 18-22.

We believe the reductions in knee flexion (Table 1) reduced the accumulated forces through the patellofemoral joint and reduced demand on the quadriceps muscles in two ways. First, reducing the knee flexion angles would directly reduce the forces applied by the extensor structure on the patellofemoral joint. Second, the initial flexion angles produced shortness in the hamstring muscles (active insufficiency), and impeded these muscles' ability to effectively contribute to the pedaling forces. After the saddle was repositioned, she noted a sensation of being able to pedal more forcefully with the posterior leg muscles and less of a sense of burning in her anterior thigh.

When the patient's pedal stroke was first visualized on the Computrainer ${ }^{T M}$, she showed a conspicuous peak in downward force on the pedals when the crank was parallel with the ground (forward stroke cycle). This force, occurring at a time when the knee was highly flexed would place a high load through the anterior knee. Upward and backward adjustment of her saddle resulted in less knee flexion at the point of forward stroke, thereby reducing compressive forces into the patellofemoral joint. This also put her in a better orientation to push forward on the pedal at top stroke, and backward, at bottom stroke. Consequently, she was able to spread the force of her stroke across a greater portion of the cycle, decreasing her previously observed peak force, but maintaining her overall power output.

The change in motor patterning for her ankle dorsiflexion/plantarflexion muscles did not occur automatically after her saddle was repositioned, but required practice. By allowing the ankle to move into dorsiflexion at top stroke, and then consciously pushing with the plantarflexors as the stroke transitioned to bottom stroke, she was able to augment force output at bottom stroke, a range in the 
stroke cycle when the quadriceps are no longer contributing to the movement (Figure 7). [Note: this technique is known as "ankling" in the general bicycling world. ${ }^{23}$ ] However, she needed feedback using sagittal plane video and torque readout on the Computrainer ${ }^{\mathrm{TM}}$ to confirm appropriate patterning. This was expected to require a period of adjustment, and she confirmed that over the first few rides on the open road, she needed to remind herself to "pedal circles instead of stomping." After 3 weeks, she was able to produce this pattern of movement without any biofeedback or cuing.

The changes made to saddle position were perceived to be significant by the patient but required time to adjust her movement pattern. With the change in saddle dimensions, she was able to relieve pressure on her perineum by spreading weight bearing throughout the ischial tuberosities. This allowed her to anteriorly tilt her pelvis, further increasing stretch of the hamstrings and shortening the rectus femorus. We would advocate making incremental adjustments instead of large changes if the patient appears to struggle with the initial changes.

All points of contact between a rider and the bicycle can be adjusted to alter positioning and joint alignment. These adjustments should all be taken into account on any rider presenting with pain that is associated with cycling. Other adjustments that could be made include arch support or varus/valgus wedging, width of pedal "stance," and angling of tibia into internal/external rotation through cleat placement. Further adjustments when a patient demonstrates a leg length discrepancy may include adding material to the sole of the shoe or placing a small plastic shim under the cleat. The rider in this case report did not appear to require any further adjustment of her footwear or compensation for leg length discrepancy.

\section{SUMMARY}

This case report describes a high-mileage rider with severe knee pain who was able to achieve pain-free riding after corrective adjustments in her alignment; specifically, raising and moving her saddle back. We believe that this positioning resulted in a reduction of patellofemoral compression and allowed her to utilize more of her lower extremity muscles to achieve satisfactory stroke power without knee pain. To fully take advantage of this improved alignment, she needed to work on modifications in her stroke mechanics using a biofeedback system for four weeks.

Clinical findings in patients who are high-mileage bicyclists and otherwise cleared of specific pathologies may be caused by misalignment of bicycle components and rider position. Any patient who demonstrates pain associated with cycling should be evaluated professionally, either by a trained "bicycle fit specialist" at a reputable bicycle shop or through a physical therapist familiar with the parameters of bicycle adjustment. Finally, alterations in bicycle fit should be made incrementally, and the cyclist should expect a period of adjustment to the new riding position.

\section{REFERENCES}

1. Bike Commuting In a Motorized World [Infographic]. Available at: http://www.laybournelawfirm.com. Linked via: http://www.ibike.org/library/statistics-data.htm . Accessed September 25, 2017.

2. Cannon DT, Kolkhorst F, Cipriani D. Effects of Pedaling techniques on muscle activity and cycling efficiency. European Journal of Applied Physiology. 2007;99(6):659-64. doi:10.1007/s00421-006-0391-6

3. Krivickas, L. Anatomical Factors Associated with Overuse Sports Injuries. Sports Medicine. 1997;24(2):132-146. https://doi.org/10.2165/00007256-199724020-00005

4. Krosshaug B, Clarsen B, Bahr R. Overuse injuries in Professional Cylists. American Journal of Sports Medicine. 2010;38(12):2494-501. doi:10.1177/0363546510376816

5. Bini RR, Hume P, Kilding A. Saddle height effects on pedal forces, joint mechanical work and kinematics of cyclists and triathletes. European Journal of Sport Science. 2014;14(1):44-52. https://doi.org/10.1080/17461391.2012.725105

6. Bini RR, Tamborindegy A, Mota C. Effects of saddle height, pedaling cadence, and workload on joint kinetics and kinematics during cycling. Journal of Sports Rehabilitation. 2010;19(3):301-14. doi:10.1123/jsr.19.3.301

7. Deakon, R. Chronic Musculoskeletal conditions associated with cycling segment of the triathlon; prevention and treatment with an emphasis on proper bicycle fitting. Sports Med Arthrosc. 2012;20(4):200-5. doi:10.1097/JSA.0b013e3182688fa0

8. How to Adjust Your Bike Seat: 12 Steps. www.wikihow.com/Adjust-Your-Bike-Seat. Accessed May 1, 2018

9. Bike Fit: Fitting A Bicycle Seat Adjustment Height Reach. http://www.jimlangley.net/crank/bikefit.html. Accessed May 1, 2018

10. Bini RR, Hume P, Lanferdini F, Vaz M. Effects of moving forward or backward on saddle on knee joint forces during cycling. Physical Therapy in Sport. 2013;14(1):23-7. doi:10.1016/j.ptsp.2012.02.003 
11. Bini, R. Patellofemoral and tibiofemoral forces in cyclists and triathletes: effects of saddle height. Journal of Science and Cycling. 2012;1(1):9-14. elSSN: 2254-7053

12. Asplund C, St Pierre P. Knee pain and bicycling. The Physician and Sportsmedicine. 2004;32(4):29-30. https://doi.org/10.3810/psm.2004.04.201

13. Computrainer: Shop the Gold Standard Now. Available at: https://www.racermateinc.com/computrainer/. Accessed July 4, 2017

14. Chapman, A R., Vincenzion, B., Blanch, P., Knox, J., Hodges, P. Leg muscle recruitment in highly trained cyclists. Journal of Sports Science. 2006;24:115-124. DOI: 10.1080/02640410500131159

15. Theurel, J, Crepin, M, Foissac, M, Temprado, JJ. Effects of different pedaling techniques on muscle fatigue and mechanical efficiency during prolonged cycling. Scandinavian Journal of Medicine \& Science in Sports. 2012;22:714721. doi:10.1111/j.1600-0838.2011.01313.x

16. Dingemans SA, Kleipool SC, Mulders MAM, Winkelhagen J, Schep NWL, Goslings JC, Schepers T. Normative data for the lower extremity functional scale (LEFS), Acta Orthopaedica. 2017;88(4):422-426. doi.org/10.1080/17453674.2017.1309886

17. Roos E, Lohmander LS. The Knee injury and osteoarthritis outcome score (KOOS): from joint injury to osteoarthritis. Health and Quality of Life Outcomes. 2003;1:64. doi:10.1186/1477-7525-1-64.

18. Chapman, A R., Vincenzino, B., Blanch, P., Hodges, P. Patterns of leg muscle recruitment vary between novice and highly trained cyclists. Journal of Electromyography and Kinesiology. 2008;18:359371. https://doi.org/10.1016/j.jelekin.2005.12.007

19. Neptune, R.R., Kautz, S.A., Hull, M.L. The effect of pedaling rate on coordination in cycling. Journal of Biomechanics. 1997;30(10):1051-1058. https://doi.org/10.1016/S0021-9290(97)00071-7

20. Hallam, I. Leg Muscles Used in the Cycling Stroke. https://skyaboveus.com/cycling/Muscles-groups-used-while-cycling. Accessed May 1, 2018.

21. Schultz, M. The Primary Muscles Used for Cycling and How to Train Them. https://www.trainingpeaks.com/blog/theprimary-muscles-used-for-cycling-and-how-to-train-them/. Accessed May 1, 2018

22. Wilson, J. Which Muscles are Really Used During the Pedal Stroke? https://www.pinkbike.com/news/Which-Musclesare-Really-Used-During-the-Pedal-Stroke-2012.html. Accessed May 1, 2018.

23. Efficiency of Pedal Stroke - Ankling. https://cyclingtips.com/2009/05/efficiency-of-pedal-stroke-ankling/. Accessed May $1,2018$.

\section{APPENDIX: NOMENCLATURE}

Bottom bracket

Mechanical system located where the down tube joins the seat tube. This consists of a transverse hollow tube containing bearings and the spindle (or axle) that connects the right crank arm to the left crank arm.

Crank arm

A rigid structure that radiates outward from the spindle and ends with the pedal. The right and left crank arms are connected across the bottom bracket by the spindle, and the two crank arms are positioned $180^{\circ}$ out of phase.

Pedal axle

The perpendicular projection at the end of each crank arm about which the pedal rotates.

Pedaling form

General alignment of the rider's upper extremities, trunk, and lower extremities. This will influence where in the stroke cycle forces are applied to the pedals and which muscles are actively contributing to the pedaling torque. 
Stroke cycle

When the bicycle is propelled, the two crank arms/pedals rotate cyclically. The right and left crank arms and pedals are always in opposite positions of the stroke cycle, i.e. $180^{\circ}$ out of phase.

Top (pedal) stroke cycle: the pedal is in uppermost position, defined as $0^{0}$ Forward (pedal) stroke cycle: the pedal is in the most forward position, $90^{\circ}$ Bottom (pedal) stroke cycle: the pedal is in the lowest position, $180^{\circ}$. 